\title{
AUDITORIA GOVERNAMENTAL BRASILEIRA: ADERÊNCIA AO FRAMEWORK DO THE INSTITUTE OF INTERNAL AUDITORS ${ }^{1}$
}

\section{BRAZILIAN GOVERNMENT AUDIT: ADHERENCE TO THE FRAMEWORK OF THE INSTITUTE OF INTERNAL AUDITORS}

\section{AUDITORÍA GUBERNAMENTAL BRASILEÑA: ADHERENCIA AL FRAMEWORK DO THE INSTITUTE OF INTERNAL AUDITORS}

Natália Gonçalves de Sousa, Mestranda do Programa de Pós-graduação em Ciências

Contábeis (PPGCont) da Universidade de Brasília (UnB). Endereço profissional:

Universidade de Brasília - FACE, Bloco B1, Sala 13/4 - Campus Darcy Ribeiro, Asa Norte,

Brasília - DF, 70910900. Telefone: (61) 31070809. URL da

Homepage: http://www.cca.unb.br/E-mail: nataliag_sousa@hotmail.com

\begin{abstract}
Abimael de Jesus Barros Costa, Professor do Departamento de Ciências Contábeis e
Atuariais e do Programa de Pós-graduação em Ciências Contábeis (PPGCont) da

Universidade de Brasília (UnB). Auditor-Chefe da Universidade de Brasília (UnB), em estágio pós-doutoral em Contabilidade Pública na Universidade de Valência/Espanha (2019-

2020). Doutor Engenharia de Transportes pela Universidade de Brasília (UnB). Endereço profissional: Universidade de Brasília - FACE, Bloco B1, Sala 13/4 - Campus Darcy Ribeiro, Asa Norte, Brasília - DF, 70910900. Telefone: (61) 31070809. URL da

Homepage: http://www.cca.unb.br/ E-mail: acosta@unb.br
\end{abstract}

\section{RESUMO}

O objetivo geral deste estudo é mensurar a aderência de $\mathrm{IN} \mathrm{n}^{\circ}$ 3/2017-CGU às Normas Internacionais de Auditoria do IIA Global. Para tanto, utilizou-se, com adaptações, a Escala Brasil Transparente criada pela Controladoria-Geral da União (CGU). Os países filiados ao Institute of Internal Auditors (IIA) têm a prerrogativa de adotar normas internacionais promulgadas pela entidade para direcionar as atividades de auditoria interna. A aplicação da análise quali-quantitativa permitiu verificar que menos da metade dos países filiados possuem adesão às normas internacionais de auditoria interna do IIA-Global. E, ainda, que em relação a aderência, no Brasil, das normas aos princípios estabelecidos na IN 3/2017-CGU, a correspondência foi superior a 90\%, porém, isso não significa adesão, mas indica que o Brasil está adotando boas práticas internacionais de auditoria interna no setor público. Essa condição proporciona maior qualidade aos trabalhos dos auditores internos corroborando a importância da atuação destes profissionais no setor público, e como consequência, a melhoria da gestão pública de maneira geral.

Palavras-chave: Auditoria Interna; Institute of Internal Auditors; Auditoria Internacional.

\section{ABSTRACT}

The general objective of this study is to measure the adherence of IN $n^{\circ} 3 / 2017-C G U$ to the International Auditing Standards of the Global IIA. For this purpose, the Transparency Scale Brasil was created by the Federal Comptroller's Office (CGU). Countries affiliated with the Institute of Internal Auditors (IIA) have the prerogative to adopt international standards

1 Artigo submetido em 13/11/2018, revisado em 16/01/2019, aceito em 11/03/2019 e divulgado em 20/10/2019 pelo EditorAlexandre Rabêlo Neto, após double blind review.

GєCont, v.6, n. 1, Floriano-PI, Jan-Jun. 2019. 
promulgated by the entity to direct internal audit activities. The application of the quantitative analysis allowed us to verify that less than half of the affiliated countries have adherence to IIA-Global's international internal audit standards. Also, in relation to adherence in Brazil to the principles set forth in IN 3/2017-CGU, correspondence was higher than 90\%, but this does not mean adherence, but indicates that Brazil is adopting good practices internal audits in the public sector. This condition gives greater quality to the work of the internal auditors, confirming the importance of the work of these professionals in the public sector, and as a consequence, the improvement of public management in general. Keywords: Internal Audit; Institute of Internal Auditors; International audit.

\section{RESUMEN}

O objetivo general está en una publicación de IN no 3/2017-CGU en Normas Internacionales de Auditoría del IIA Global. Para tanto, utilice, se adapta a Escala Brasil Transparente criada pela Controladoria-Geral da União (CGU). Os países filiados ao Instituto de Auditores Internos (IIA) es una prerrogativa de las normas internacionales promisorias de las personas para dirigir las actividades de auditoría interna. La aplicación de la cualificación cualitativa permite obtener menos datos de los países en los que se aplican las normas internacionales de auditoría interna del IIA-Global. E, ainda, que em relação a aderência, no Brazil, das normas aos princípios estabelecidos na 3/2017-CGU, una correspondencia foi superior a 90\%, por lo, isso não significa adesão, mas indica que o Brazil está adotando boas práticas Internacionais de auditoria interna no setor público. Esta condición proporciona mayor calidad a los trabajos de los auditores internos corroborando la importancia de la actuación de estos profesionales en el sector público, y como consecuencia, la mejora de la gestión pública de manera general.

Palabras-clave: Auditoria Interna Institute of Internal Auditors; Auditoria Internacional.

\section{INTRODUÇÃO}

$7 \mathrm{~m}$ atenção ao disposto pela Constituição Federal referente às normas financeiras, orçamentárias, operacionais e patrimoniais da União, a Lei $\mathrm{n}^{\circ}$ 10.180, de 6 de fevereiro de 2001 e o Decreto $n^{\circ} 3.591$, de 6 de setembro de 2000, disciplinaram a organização, as finalidades e a estrutura do Sistema de Controle Interno (SCI), no âmbito do Poder Executivo Federal.

O Decreto-Lei $\mathrm{n}^{\circ}$ 200/67 definiu como fundamental o controle para o exercício das atividades públicas federais, sendo um dos pilares, a auditoria interna. Independente do ambiente ou da função exercida pela entidade pública, é imprescindível que haja critérios claros e específicos para um controle objetivo e transparente, com foco no aperfeiçoamento das ações realizadas.

O Brasil, como filiado ao Institute of Internal Auditors (IIA), tem a prerrogativa de adotar as normas internacionais de auditoria interna também para o Setor Público, visando a convergência e harmonização das normas internas de auditoria. No entanto, só em 2017, a CGU atentou-se em estabelecer critérios que incorporassem práticas internacionais às normas brasileiras, com o intuito de proteger e ampliar o valor organizacional das instituições públicas.

O Poder Executivo Federal, em busca de maiores controles e transparência, editou através do Ministério da Transparência e Controladoria-Geral da União (CGU) em 2017, a Instrução Normativa $n^{\circ} 3$, que aprovou o Referencial Técnico a respeito de normas internas de auditoria com o propósito de unificar e alinhar as orientações acerca de princípios, diretrizes e práticas para todos os entes representantes das atividades públicas, direta e indiretamente.

GєCont, v.6, n. 1, Floriano-PI, Jan-Jun. 2019. 
Segundo o Ministério da Transparência e Controladoria-Geral da União (CGU), através da avaliação e consultoria baseadas em risco, é possível absorver os procedimentos consolidados internacionalmente ao normativo nacional com a finalidade de que o Brasil tenha maiores competências na área de controle e maiores níveis de transparência.

Nesse contexto, surge a questão de pesquisa do presente estudo: quais aspectos, a partir da edição da IN n 3/2017-CGU, podem indicar que o Brasil está em aderência com as normas internacionais de auditoria interna do IIA? Com o intuito de responder essa questão, o objetivo geral deste artigo é mensurar a aderência de IN $\mathrm{n}^{\circ}$ 3/2017-CGU às Normas Internacionais de Auditoria do IIA Global.

Para alcance do objetivo geral, foram construídos os seguintes objetivos específicos: Destacar a experiência internacional da adoção das normas internacionais de auditoria interna do IIA-Global; e (b) realizar uma análise sobre a Instrução Normativa no 3/2017/CGU à luz das normas de auditoria interna internacionais editadas pelo IIA.

A pesquisa torna-se relevante porque busca a verificação da adoção das normas internacionais no Brasil, considerando a IN no 3/2017-CGU, e as ações decorrentes da necessidade de implementar mais ações e avaliar reflexos para o setor público ensejando em maiores níveis de eficiência, transparência e comparabilidade. Assim, esta pesquisa contribuirá para verificar e avaliar as ações de auditoria interna na atividade governamental e, por conseguinte, o progresso decorrente da maior adequação do Brasil às normais internacionais de auditoria interna, considerando de maneira especial as experiências internacionais.

Esta investigação está estruturada em cinco partes, sendo esta introdução a primeira delas, contemplando a introdução ao tema, o problema de pesquisa, a justificativa e os objetivos do estudo. Na seção seguinte, é realizada revisão de literatura sobre a Instrução Normativa $\mathrm{n}^{\circ} 3 / 2017$, auditoria interna e a relação do Brasil e do Mundo com a auditoria interna no setor público. Na terceira, são apresentados os procedimentos metodológicos adotados na pesquisa. Na quarta, é apresentada a análise descritiva e os resultados dos dados colhidos e necessários à discussão, bem como à resposta da indagação realizada. E, finalmente, na última parte são feitas as considerações finais sobre o estudo.

\section{FUNDAMENTAÇÃO TEÓRICA}

\subsubsection{Isomorfismo Coercitivo}

Inicialmente, a definição de Machado-da-Silva e Gonçalves (1999) de que a Teoria Institucional é o resultado das influências decorrentes da ciência política, da sociologia e da economia, que estabelecem conceitos padronizados de valores, normas e comportamentos, para as organizações e os indivíduos, corrobora o institucionalismo e seus desdobramentos como a teoria capaz de compreender as estruturas e procedimentos que envolvem as alterações no setor público em relação a auditoria interna.

Adicionalmente, o ponto de central da teoria institucional está na legitimidade, que, segundo Ruef e Scott (1998), pode ser definida como uma condição que traduz o posicionamento cultural, o suporte normativo em consonância com regras e leis relevantes. A perspectiva regulatória contempla, conforme Scott (1995), que as estruturas são os principais portadores das regras institucionais, sendo os elementos normativos as condições ambientais que afetam o processo. O que estabelece a importância do regramento instrucional em busca de legitimidade, especialmente, no âmbito das instituições públicas.

Entre as divisões existentes na Teoria Institucional, a Nova Sociologia Institucional, segundo Hoque (2010), pressupõe estruturas e procedimentos intraorganizacionais que em maior parte decorrem de fatores externos. Essa influência externa reflete nas regras, procedimentos e normas que as organizações adotarão em razão das mudanças sociais 
(MEYER; SCOTT; DEAL, 1983). Dentro Nova Sociologia Institucional, existe a subdivisão em isomorfismos que DiMaggio e Powell (1983) explicam haver por uma tendência de que as organizações se tornem homogêneas adotando as mesmas estruturas e práticas, e podem ser de três formas - o coercitivo, o mimético e o normativo - apresentando as formas pelas quais podem ser disseminados os resultados institucionais dentro das organizações.

Por se tratar de uma entidade que direciona as condutas dos auditores internos através de aconselhamentos, a relação entre o IIA e signatários apresentando a necessidade de equalizar as normas com o objetivo de facilitar a interpretação e atuação das organizações pode resultar no isomorfismo coercitivo, que deriva da perspectiva regulatória em busca por legitimidade. Para DiMaggio e Powell (2005), o isomorfismo coercitivo decorre tanto de pressões formais quanto de pressões informais exercidas sobre as organizações por outras organizações das quais elas dependem, e pelas expectativas culturais da sociedade em que as organizações atuam. Tais pressões podem ser sentidas como coerção, como persuasão, ou como um convite para se unirem em conluio. Em algumas circunstâncias a mudança organizacional é uma resposta direta a ordens governamentais. Ainda segundo os autores essa postura organizacional faz com que as instituições fiquem parecidas, fenômeno definido como isomorfismo.

DiMaggio e Powell (2005) pontuam também que o isomorfismo coercitivo se origina de influências políticas e de problemas de legitimidade. Um resultado das pressões formais e informais sofridas pelas organizações podendo ser através ou por expectativas culturais da sociedade, dentro da qual uma organização se encontra inserida. Nesse tocante, a convergência das normas internacionais de contabilidade do IASB, para o mundo financeiro, e do IFAC, para os governos, pode ser explicada pela Teoria Institucional, no pilar do Isomorfismo Coercitivo. Algo similar está acontecendo com as Normas Internacionais de Auditoria Interna do IIA-Global.

A partir desse entendimento, Pires (2018) conclui que as organizações podem adotar novas condutas e procedimento em razão de regulamentações governamentais. A existência de um direcionamento externo implica em alteração de todas as condutas que estejam atreladas a esse direcionamento. Assim, qualquer mudança de conduta organizacional com a finalidade de atender um regramento imposto por autoridade governamental, seria uma busca por legitimidade através de isomorfismo coercitivo. Dessa forma, indicam DiMaggio e Powell (1983, p. 151), "a expansão do Estado, a centralização do capital e a coordenação da filantropia suportam a homogeneização de modelos organizacionais através de relações de autoridade direta".

\subsubsection{Normas Internacionais de Auditoria Interna - IIA Global}

O órgão responsável por direcionar internacionalmente as ações dos auditores internos é o The Institute of Internal Auditors (IIA). O Instituto é uma associação profissional internacional que possui representantes em diversos países do mundo com a finalidade de normatizar a auditoria interna, possui representação no Brasil, é uma entidade sem fins lucrativos com o escopo de proporcionar serviços de formação, capacitação e certificação.

Conforme o IIA, a auditoria interna é uma atividade independente e objetiva de avaliação e consultoria, com o intuito de valorizar e melhorar as operações de uma entidade. E com uma abordagem ordenada eleva a eficácia dos processos de gerenciamento de risco, controle e governança. Isto posto, observa-se a importância de buscar uniformidade entre as normas praticadas internacionalmente.

O IIA estabelece uma categorização entre as normas de auditoria interna, sendo normas de Atributo e Normas de Desempenho. Normas de Atributo, são aquelas que correspondem as características da organização e dos indivíduos responsáveis pela execução 
da auditoria; e as Normas de Desempenho, tratam da natureza da auditoria interna e fornecem critérios de qualidade do desempenho.

O papel da Auditoria Interna no setor público, ainda, que guarde afinidades com a Auditoria Independente ou Auditoria Externa, tem especificidades relacionadas, especialmente a como analisar e obter informações decorrentes da utilização de recursos públicos, com transparência, prestação de contas e responsabilização; melhoria de serviços públicos através de avaliações dos programas de governo; e proteção ao patrimônio público. (Manual de orientações técnicas da atividade de auditoria interna governamental do Poder Executivo Federal, 2017)

Segundo Seeuws (2014), os trabalhos de auditoria interna podem ser divididos em dois tipos, o de avaliação e o de consultoria. O de avaliação fornece opinião, conclusão ou os dois, e se refere ao funcionamento da organização. $O$ de consultoria é uma forma de melhorar a organização através de recomendações, geralmente, provenientes do gestor. Sendo que, para ela:

\footnotetext{
A auditoria interna é uma atividade independente e objetiva de avaliação e consultoria, designada para agregar valor e aprimorar as operações de uma organização. Ela auxilia a organização a realizar seus objetivos a partir de uma abordagem sistemática e disciplinada para avaliar e melhorar a eficácia dos processos de gerenciamento de riscos, controle e governança. (SEEUWS, 2014, p.52).
}

A auditoria interna está intrinsicamente ligada ao controle interno, e deve se adaptar o nível de maturidade existente neste. A auditoria interna vai praticar e promover o desenvolvimento o controle interno, onde existe baixa maturidade. Ao passo que onde é maior evolução, o objetivo estará assentado em aprimorar a governança e o gerenciamento de risco. (SEEUWS, 2014).

A auditoria interna, deve proporcionar aceitável segurança à administração e à sociedade que são as partes interessados dos trabalhos realizados. Para tanto, é necessário que a auditoria interna do setor público execute o que está estabelecido nas normas destinadas a orientar os trabalhos, bem como contribua e se adapte. Com a finalidade de alcançar além de objetivos estratégicos, melhorar os resultados e agregar valor à organização de forma geral. (SEEUWS, 2014). O recorte do papel da auditoria interna, principalmente, na ótica do setor público é incipiente no Brasil. Porém, na literatura internacional, esse tema é explorado à luz das normas The Institute of Internal Auditors - IIA (CHRIST et al., 2015; MARKS, 2012; VINTEN, 2004).

\subsubsection{Paradigma das Normas Internacionais de Auditoria Interna no Brasil}

Os padrões internacionais de auditoria interna são definidos pelo The Institute of Internal Auditors - IIA. Fundado em 1941, trata-se de uma associação profissional internacional que atua como voz global do profissional de auditoria interna. Atualmente, o IIA tem mais e 185.000 membros no mundo e afiliados em 123 países. No Brasil, é representando pelo Instituto dos Auditores Internos do Brasil - IIA Brasil, que dentre os filiados, está entre os cinco mais atuantes no mundo (COSTA; ALVES, 2017; IIA, 2017).

Figura 1 - International Professional Practices Framework - IPPF

GєCont, v.6, n. 1, Floriano-PI, Jan-Jun. 2019. 


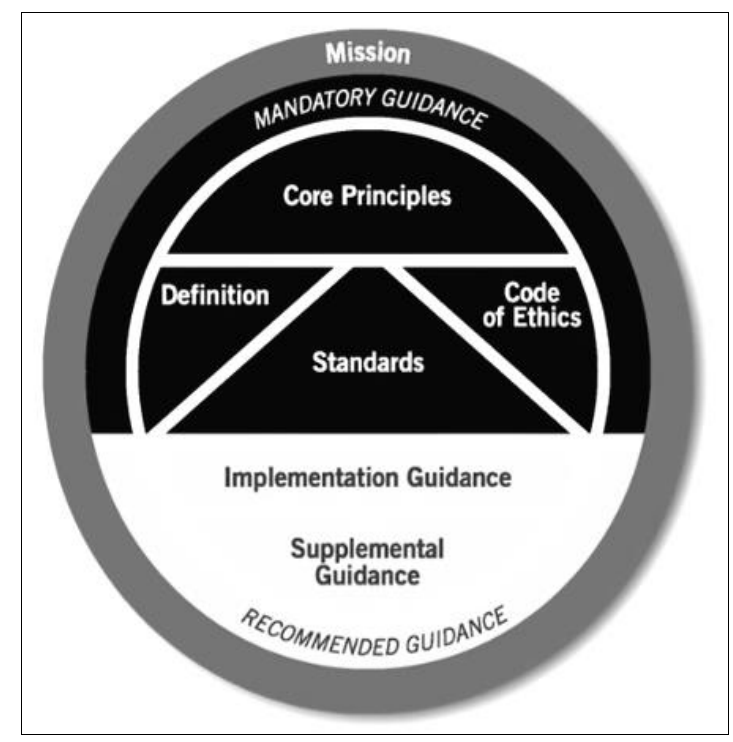

Fonte: IIA - Brasil (2017)

A base conceitual que organiza as informações oficiais promulgadas pelo IIA é chamada de International Professional Practices Framework - IPPF. Conforme Figura 1, os métodos e orientações da IPPF são organizados em dois grupos subdivididos em seis categorias: 1) Orientações mandatórias compostas por: Princípios Fundamentais, Definição, Normas e Código de ética; 2) Orientações recomendadas compostas por: Orientações de Implantação e Orientações Suplementares (IIA, 2017).

Neste novo paradigma de normas internacionais, a sociedade, tendo maior acesso a informações exige maior qualidade nos serviços públicos, cobra maior transparência, responsabilidade e prestações de contas coerentes das organizações públicas. Essas demandas implicam em maiores responsabilidades para as unidades de auditoria interna nas instituições públicas. No Brasil, após a edição legislações que dispõem sobre o acesso à informação e sobre controles internos, gestão de riscos e governança no âmbito do Poder Executivo Federal, vislumbrou-se diversas atribuições para a atividade de auditoria interna governamental, ensejando em maior exposição da figura do auditor, bem como uma maior contribuição nas tomadas de decisão, tendo sua relevância reconhecida pelo nível estratégico das organizações.

Ao passo que essas mudanças geram aumento da responsabilidade em dar resposta adequada aos anseios da sociedade, exigindo que os auditores internos governamentais adquiram novas habilidades, adotem novas estratégias e, consequentemente, prestem maior variedade de serviços, espera-se que a auditoria interna contribua cada vez mais para o aprimoramento da governança de órgãos e entidades.

Na Figura 2, abaixo, percebe-se que as normas do IIA estão mais expostas e claras nos Estados Unidos.

Figura 2 - Resposta global à exposição de mudanças às normas internacionais 


\section{para o profissional de auditoria interna}

Fonte: Relatório Anual 2016: Celebrando Sucessos. Abraçando desafios. IIA Global (2017, p. 6)

A figura 2 - Resposta global à exposição de mudanças às normas internacionais para o profissionalde auditoria interna, exemplifica como tem sido a reação dos países em relação as normas internacionais. Nesse contexto, tem-se no Brasil o Ministério da Transparência e Controladoria-Geral da União (CGU), que é o órgão do Governo Federal responsável por realizar atividades relacionadas à defesa do patrimônio público e ao incremento da transparência da gestão, por meio de ações de controle interno, auditoria pública, correição, prevenção e combate à corrupção e ouvidoria.

Através de Instruções Normativas, a partir de 2001, a CGU, vem disciplinando as normas de Auditoria Interna Governamental, na esfera federal no Brasil, conforme Quadro 1, que apresenta o histórico das publicações referentes à competência da CGU em editar as normas de auditoria interna para o setor público no Brasil. Onde pode-se visualizar todas as transformações.

\section{Quadro 1 - Cronologia das Diretrizes da CGU a respeito das Auditorias Internas} governamentais

\begin{tabular}{|c|c|c|c|c|c|}
\hline 2001 & 2006 & 2007 & 2015 & \multicolumn{2}{|c|}{2017} \\
\hline IN N. ${ }^{\circ} 01$ & IN N $^{\circ} 07$ & IN No 01 & IN No 24 & IN N 3 & IN N 8 \\
\hline $\begin{array}{l}\text { Define } \\
\text { diretrizes, } \\
\text { princípios, } \\
\text { conceitos e } \\
\text { aprova normas } \\
\text { técnicas para a } \\
\text { atuação do } \\
\text { Sistema de } \\
\text { Controle } \\
\text { Interno } \\
\text { Poder do } \\
\text { Executivo } \\
\text { Federal. }\end{array}$ & 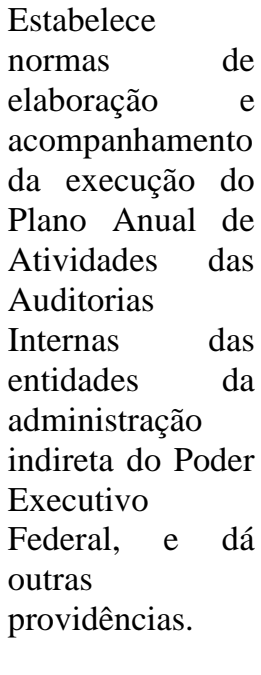 & $\begin{array}{l}\text { Estabelece o } \\
\text { conteúdo do } \\
\text { Plano Anual } \\
\text { de Atividades } \\
\text { de Auditoria } \\
\text { Interna e do } \\
\text { Relatório } \\
\text { Anual de } \\
\text { Atividades de } \\
\text { Auditoria } \\
\text { Interna. }\end{array}$ & $\begin{array}{lr}\text { Dispõe sobre o } \\
\text { Plano Anual de } \\
\text { Auditoria } \\
\text { Interna } \\
\text { (PAINT), os } \\
\text { trabalhos } \\
\text { auditoria } \\
\text { realizados } \\
\text { unidades pelas } \\
\text { auditoria interna } \\
\text { e o Relatório } \\
\text { Anual de } \\
\text { Atividades da } \\
\text { Auditoria da } \\
\text { Interna (RAINT) } \\
\text { e dá outras } \\
\text { providências. }\end{array}$ & $\begin{array}{l}\text { Aprova } \\
\text { Referencial } \\
\text { Técnico da } \\
\text { Atividade de } \\
\text { Auditoria } \\
\text { Interna } \\
\text { Governamental } \\
\text { do Poder } \\
\text { Executivo } \\
\text { Federal. }\end{array}$ & $\begin{array}{lr}\text { Aprova } & \text { o } \\
\text { Manual } & \text { de } \\
\text { Orientações } & \\
\text { Técnicas } & \text { da } \\
\text { Atividade } & \text { de } \\
\text { Auditoria } & \\
\text { Interna } & \\
\text { Governamental } \\
\text { do Poder } \\
\text { Executivo } \\
\text { Federal. }\end{array}$ \\
\hline
\end{tabular}

Fonte: Elaborado pelos autores.

Depois de apresentar aspectos teóricos e institucionais relacionados com o fenômeno desta pesquisa, na próxima seção serão detalhados os procedimentos metodológicos.

\section{PROCEDIMENTOS METODOLÓGICOS}

Para atender aos objetivos da investigação, esta metodologia foi dividida em duas partes. Sendo a primeira delas uma pesquisa documental e qualitativa referente à adoção das normas internacionais de auditoria do IIA ao redor do mundo. E a segunda uma metodologia quali-quantitativa para verificar a aderência às normas internacionais que foi adotada no Brasil para o setor público com a publicação da IN 3/2017-CGU.

Considerando dados disponibilizados pelo IIA, foi elaborada uma tabela com membros filiados, onde define-se como "adotado" - quando as normas são adotadas em sua integralidade, "parcialmente adotado" - quando as normas são adotadas em partes, "em processo" - quando estão em processo de adoção, "não adotado" - quando não são adotadas e "informação não disponível” - nos casos em que não é apresentada a informação. Sendo 
assim, serão considerados, para fins deste estudo "adotado", "parcialmente adotado", "em processo" como países que aderem às normais internacionais e os demais como sendo os países que não aderem.

Para criar um panorama verificável e passível de comparação foi adaptado a Metodologia de Avaliação - Escala Brasil Transparente criada pela CGU. Que tinha como objetivo realizar a avaliação de níveis de transparência existentes no Brasil.

Nesta pesquisa, as normas foram divididas em categorias. Conforme o estabelecido pelo IIA entre Normas de Atributo e de Desenvolvimento, onde cada um dos itens divulgados foram listados e pontuados com a intenção de verificar a sua correspondência às normas editadas na $\mathrm{IN} \mathrm{n}^{\mathbf{0}}$ 3/2017-CGU.

A aplicação da metodologia da CGU consiste em estabelecer uma métrica, a qual foi criada baseada nas normas estabelecidas pelo IIA. São 52 proposições, sendo que 19 correspondem às Normas de Atributos e 33, às Normas de Desenvolvimento. Dessa forma, os pesos foram atribuídos proporcionalmente, onde $40 \%$ da nota foi destinada para as Normas de Atributos e $60 \%$ para as Normas de Desenvolvimento. Com o objetivo de diminuir subjetividades o cálculo consiste em verificar através de apenas dois tipos de resposta "SIM" ou "NÃO", a correspondência das normas estabelecidas pelo IIA e a correspondência na publicação realizada pela CGU da IN No 3/2017.

Para fins de aferição da pontuação, todos os itens avaliados têm uma pontuação correspondente estabelecida unicamente pela relevância da norma, sendo 100 e 200 pontos, com base na percepção do elaborador de maior ou menor relevância, que se soma ao cálculo da nota, até uma pontuação máxima de 6500 pontos. Em regra, a resposta SIM, representada por 1, gera pontuação máxima do quesito e a resposta $\mathrm{N} \tilde{A} \mathrm{O}$, representada por 0 , gera nenhuma pontuação.

Foram atribuídas notas 200 aos itens, pertencentes às Normas de Atributos - Programa de Garantia de Qualidade e Melhoria, Requerimentos do Programa de Garantia de Qualidade e Melhoria, Avaliações Internas, Avaliações Externas, Reporte do Programa de Garantia de Qualidade e Melhoria, Uso de "Em conformidade com as Normas Internacionais para a Prática Profissional de Auditoria Interna", Divulgação de Não Conformidade; e às Normas de Desenvolvimento - Planejamento do Trabalho de Auditoria Interna, Considerações sobre o Planejamento, Objetivos do Trabalho da Auditoria, Escopo do Trabalho da Auditoria, Alocação de Recursos para o Trabalho da Auditoria, Programa de Trabalho da Auditoria. Para os demais itens foram atribuídas notas 100. Sendo que os itens de maior valor possuem esta classificação em razão da sua relevância para a execução da atividade de auditoria interna.

A nota final é obtida convertendo-se da base 6500 para a base percentual, onde o resultado expõe a porcentagem de normas internacionais estão presentes na IN editada pela CGU, proporcionando uma visualização numérica da aderência das normas internacionais de auditoria para o setor público brasileiro, conforme Fórmula 1.

$$
\text { Aderência Total }(\mathrm{AT})=\sum \text { (Pontuação Atingida / 6500) x } 100 \text { (1) }
$$

\section{DESCRIÇÃO E ANÁLISE DE DADOS}

\subsubsection{Resultados Verificados Quanto à Adoção Internacional}

De acordo com o IIA, os 124 países que possuem membros filiados, são aconselhados a usar as normas. Observa-se, no entanto, uma recomendação e não uma obrigatoriedade. Além disso, as normas são direcionadas aos auditores e não necessariamente a instituições, que optam por adotá-las de acordo com as suas necessidades e realidades. Dos 124 países onde o IIA possui sede, somente 55 adotam integralmente as normas de auditoria interna de 
acordo com o IFAC. O que traduz uma aderência de menos de 50\% dos países listados no Quadro 2.

\section{Quadro 2 - Adoção Internacional das Normas de Auditoria Interna do IIA- Global}

\begin{tabular}{|l|c|c|}
\hline \multicolumn{1}{|c|}{ Países pesquisados } & Status & $\sum$ \\
\hline Albânia, Armênia, Áustria, Bahamas, Bangladesh, Barbados, Bélgica, & & \\
Bósnia e Herzegovina, Botsuana, Brasil, Bulgária, Camarões, Costa Rica, & & \\
Croácia, Dinamarca, Finlândia, Gana, Grécia, Guiana, Hong Kong, China, & & \\
Islândia, Indonésia, Irlanda, Itália, Jamaica, Jordânia, Quénia, Líbano, & & \\
Lesoto, Lituânia, Malawi, Malásia, Maurícia, México, Montenegro, Holanda, & Adotado & \\
Nigéria, Paquistão, Peru, Portugal, Ruanda, Arábia Saudita, Sérvia, & & \\
$\begin{array}{l}\text { Eslovênia, África do Sul, Suazilândia, Rep. Unida da Tanzânia, Togo, } \\
\text { Trinidad e Tobago, Tunísia, Uganda, Ucrânia }\end{array}$ & \\
Reino Unido e Irlanda, Zâmbia e Zimbabwe & & \\
\hline $\begin{array}{l}\text { Austrália, Bahrein, Bolívia, Canadá, China, República Tcheca, República } \\
\text { Dominicana, Estônia, França, Alemanha, Hungria, Índia, Israel, Japão, } \\
\text { República da Coreia, Letônia, Luxemburgo, Macedónia, Nova Zelândia, } \\
\text { Nicarágua, Noruega, Panamá, Filipinas, Singapura, Espanha, Suécia, } \\
\text { Tailândia, Estados Unidos e Vietnã }\end{array}$ & Em processo & 29 \\
\hline Chile e Haiti & & \\
\hline $\begin{array}{l}\text { Afeganistão, Angola, Aruba, Bermudas, Rep. Dem. do Congo, Costa do } \\
\text { Marfim, Curaçao, Equador, Etiópia, Mali, Moçambique, Níger, Omã, Porto } \\
\text { Rico, Qatar, Turquia, Ilhas Turks e Caicos, Emirados Árabes Unidos, Iêmen }\end{array}$ & Não disponível & 19 \\
\hline
\end{tabular}

Fonte: elaborados pelos autores

Nesse contexto, também se observa que no setor público as normas são bem menos utilizadas nos países filiados ao IIA. De acordo com os dados coletados, apenas 8 , do total de 124 países, adotam as normas internacionais para o setor público. O que corresponde a aproximadamente $6,5 \%$ de adoção em âmbito mundial.

Ao se expandir a visualização para os países que estão "em processo" de adoção e onde as normas são "parcialmente adotadas", o nível de aderência se eleva substancialmente. No caso das normas internacionais para o setor público o percentual de aderência atinge próximo de $60 \%$, e para a auditoria interna $83,06 \%$, de adesão.

Essa aderência, seja de países ainda em processo, em adoção parcial, ou adoção total, demonstra um direcionamento que os países têm seguido, o que proporciona maiores condições de possíveis convergências e harmonizações das normas internacionais.

Por fim, verificou-se a aderência no Brasil apesar das normas internacionais de auditoria interna do IIA não serem adotadas pela CGU e o CFC. No entanto, pode-se observar que diversos princípios da Instrução Normativa n. 3 da CGU, correspondem às normas decorrentes do IIA. O percentual de aderência total calculado foi de 92,31\%, sendo proporcionalmente maior nas Normas de Desempenho. Esses dados são apresentados através do modelo matemático desenvolvido pela CGU (APÊNDICE A).

\subsubsection{Aderência às Normas de Atributos}

Estão relacionadas as características das organizações e das partes. $\mathrm{Na}$ análise realizada com a aplicação da metodologia estabelecida, verificou-se aderência de 36,92\%, considerando o percentual (40\%) máximo estabelecido no modelo. No que se refere a norma Propósito, Autoridade e Responsabilidade (1000), a Instrução Normativa da CGU, detalha como um de seus princípios a Integridade. Compreendendo que os auditores devem possuir conduta ética e comportamento íntegro, ressaltando que além de servir ao interesse público de forma honesta com diligência e honestidade, é fundamental ao auditor interno governamental a observância da lei. Sendo, portanto, um princípio correspondente à norma internacional.

GєCont, v.6, n. 1, Floriano-PI, Jan-Jun. 2019. 
As normas Independência e Objetividade (1100), Independência Organizacional (1110), Interação direta com o Conselho (1111), Papéis do executivo chefe de auditoria além da auditoria interna (1112), Objetividade Individual (1120) e Prejuízo à Independência ou Objetividade (1130) estão previstas na IN/CGU e a instrução prevê a Autonomia Técnica e Objetividade. Onde estão previstas autonomia técnica e objetividade, a comunicação direta com o Conselho para dirimir ocasionais interferências, o desenvolvimento do trabalho de maneira imparcial e isenta com o intuito de evitar conflito de interesses. Quanto as possíveis atribuições externas também há previsão de haja salvaguardas para que se limite eventuais prejuízos. Atendendo todos os itens da norma internacional.

Ainda, existe uma previsão de sigilo profissional, considerando a atividade governamental a referida Instrução prevê que o profissional de auditoria interna atuante no setor público, utilize as informações as quais tem acesso somente para fins oficiais. Ainda, o conjunto de normas de Proficiência e Zelo profissional Devido (1200), neste contexto, também, apresenta correspondência na IN/CGU, que pontuou também a necessidade de os auditores internos governamentais observarem princípios que ensejam na capacidade de realizar os trabalhos para os quais foram designados com compreensão e experiência, demonstrando diligência e responsabilidade no desempenho das tarefas, bem como prezar pelo aperfeiçoamento de seus conhecimentos, habilidades e outras competências, por meio do desenvolvimento profissional contínuo.

As normas relacionadas com o Programa de Garantia de Qualidade e Melhoria (1300) com correspondente destas normas, a IN/CGU preceitua, dentro do capítulo que trata do gerenciamento da atividade de auditoria interna governamental, uma seção destinada Gestão e Melhoria da Qualidade, que contempla a instituição de um programa que atenda a necessidade de gestão e monitoramento através de avaliações interna e externas, para verificação da qualidade e possíveis melhorias. Da mesma forma que foi elaborada a norma internacional, a IN prevê as autoavaliações e periodicidade das avaliações internas, bem como externas. E, também, as informações destas avaliações à alta administração pelo responsável pela Unidade de Auditoria Interna Governamental. Sendo que as não conformidades também devem ser informadas, inclusive ao Conselho, se houver.

Este princípio não contemplou as conformidades com as normas internacionais. O que pode ser compreendido facilmente considerando que o instrumento de normatização é justamente a própria instrução.

\subsubsection{Aderência às Normas de Desempenho}

Apresentam a natureza das atividades com critérios para avalição. $\mathrm{Na}$ análise realizada com a aplicação da metodologia estabelecida, verificou-se aderência de 55,38\%, dentre os $60 \%$ disponíveis. No que se refere ao conjunto de normas de Gerenciamento da Atividade de Auditoria Interna (2000), o Capítulo IV, da Instrução Normativa, é destinado exclusivamente para tratar do Gerenciamento da Atividade de Auditoria Interna Governamental, sendo que para alcançar este objetivo foram estabelecidos o atendimento a itens que da mesma forma que a norma internacional, adicionem valor à unidade auditada. Esse capítulo foi divido em seções, que contemplam assuntos como Gestão e Melhoria da Qualidade, Planejamento, Comunicação e Aprovação do Plano de Auditoria Interna e Objetivos dos Trabalhos.

Os pontos previstos na norma internacional estão previstos especificamente na seção II, que trata do Planejamento, Comunicação e Aprovação do Plano de Auditoria Interna, a maioria dos itens possui correspondência a exceção da previsão de Prestadores de Serviço Externo e a Responsabilidade da Organização sobre a Auditoria Interna e da Confiança, condições que se auto justificam por se tratar de normas para instituições públicas onde não há espaços para subjetividades e atores externos. 
Existe a previsão de contemplar o Planejamento, a Comunicação e Aprovação, o Gerenciamento de Recursos, as Políticas, Procedimentos e Coordenação, e o Reporte para a Alta Administração e o Conselho. Como o item da Coordenação e Confiança é único na norma internacional, foi atribuído "NÃO" na avaliação de correspondência, justamente porque a metodologia prevê que caso não haja correspondência total, a premissa se torna inválida.

O conjunto de normas de Natureza do Trabalho (2100) está previsto na Instrução Normativa preceitua que a avaliação da eficácia, tanto de Gerenciamento de Riscos, quanto do Controle, é necessário que os sistemas contemplem o alcance dos objetivos estratégicos; da confiabilidade e da integridade das informações; da eficácia e da eficiência das operações e programas; da salvaguarda de ativos; da conformidade dos processos e estruturas com leis, normas e regulamentos internos e externos. Dessa forma, essa norma foi plenamente a recepcionada nos princípios elencados pela CGU.

As normas de Planejamento do Trabalho de Auditoria Interna (2200) estão previstas no capítulo que trata da Operacionalização dos Trabalhos de Auditoria. A partir da seção I, encontram-se os correspondentes das normas que definem que para cada trabalho de auditoria, os auditores devem desenvolver e documentar um planejamento com os principais pontos de orientação das análises a serem realizadas. Nos itens subsequentes, a IN também detalha as Considerações sobre o Planejamento (2201), Objetivos do Trabalho da Auditoria (2210), Escopo do Trabalho da Auditoria (2220), Alocação de Recursos para o Trabalho da Auditoria (2230) e Programa de Trabalho da Auditoria (2240). Apontando a preocupação do órgão de controle em direcionar a realização planejada dos trabalhos dos auditores governamentais. Esse planejamento está diretamente apoiado na necessidade de realização de um trabalho eficaz e eficiente, com a definição de objetivos, forma de realização, recursos necessários e procedimentos para alcance do que foi previamente estabelecido.

As normas de Execução do Trabalho da Auditoria (2300) que determinam a necessidade de identificar, analisar, avaliar e documentar informações suficientes para cumprir os objetivos do trabalho da auditoria. Assim como o IIA, a CGU instruiu a partir da seção II, ainda no capítulo sobre Operacionalização dos Trabalhos de Auditoria, como cumprir tais objetivos. As normas de Comunicação dos Resultados (2400) são itens com aplicação e correspondência na IN, conferindo a este princípio a prerrogativa de comunicar o resultado dos trabalhos com precisão, objetividade, clareza, concisão, de forma completa, construtiva e tempestiva, informando possíveis erros e omissões e qualquer não conformidade com as diretrizes estabelecidas no Referencial Técnico.

No entanto, a própria Instrução é o documento regulador para as regras a serem seguidas na auditoria interna pública, por este motivo o Uso de "Conduzido em Conformidade com as Normas Internacionais para a Prática Profissional de Auditoria Interna” (2430), não possui correspondente na IN.

O conjunto de normas de Monitoramento do Progresso (2500) tem consonância IN, considerando que é estabelecido adotar sistemas que quantifiquem os registros dos resultados e os benefícios da sua atuação, com a adoção de princípios e metodologia adequados a regulamentação pelo órgão central do SCI permitindo consolidação. As normas de Comunicação da Aceitação de Riscos (2600) são encontradas no Referencial Técnico dentro da seção que trata do Monitoramento, onde é preceituado que se a Unidade de Auditoria Interna Governamental, verificar a responsabilidade da unidade auditada em um nível de risco que pode ser inaceitável, o auditor deve discutir o assunto com a alta administração ou o conselho, se houver.

Por fim, após a descrição e análise dos achados descrito acima, na próxima seção serão apresentadas as considerações finais do estudo, e as contribuições em relação a atribuição de valor às instituições a partir da atividade de auditoria interna. 


\section{CONSIDERAÇÕES FINAIS}

Este artigo se propôs a demonstrar a situação atual das normas internacionais de auditoria interna no setor público brasileiro, considerando para isso um panorama da situação mundial sobre o tema. Apoiado em pressupostos da teoria institucional, especialmente, o isomorfismo coercitivo, as alterações realizadas internacionalmente e a evolução da auditoria interna pública no Brasil, evidenciou-se o avanço brasileiro em busca de maior legitimidade em relação as normas internacionais no aspecto da auditoria interna no setor público. $\mathrm{O}$ que apresenta um posicionamento atualizado dos normatizadores governamentais em busca de um alinhamento com os parâmetros adotados internacionalmente.

Diante dos dados analisados, ficou demonstrado que o Brasil evoluiu na adoção de normas de auditoria interna internacionais ao longo dos anos. Mas, especialmente, no ano de 2017, com a edição da IN n ${ }^{\circ}$, a CGU proporcionou uma aderência quase total às normas internacionais. Excetuando-se somente as normas que se relacionavam exclusivamente com a necessidade de seguir o normativo emitido pelo IIA, que não apresenta relevância no contexto brasileiro.

A maior contribuição deste movimento de internacionalização em relação as práticas de auditoria interna, está apoiada na contribuição que as auditorias internas têm de gerar valor às instituições das quais elas fazem parte. Assim, o setor público brasileiro ao assemelhar as normas de atuação dos auditores internos aos padrões adotados internacionalmente, demonstra uma busca de maior qualidade na gestão pública e consequentemente o fortalecimento destas instituições.

O foco desta pesquisa difere-se das demais ao analisar uma normatização recente e verificar quais países também caminham para apresentar as mesmas prerrogativas, traçando um panorama entre o que tem sido o posicionamento brasileiro em relação aos demais países do mundo. Foram relacionadas a experiência internacional na adoção das normas do IIA com o processo de convergência dos IFRS do IASB; e mensurada a aderência de IN no $3 / 2017$ CGU às Normas Internacionais de Auditoria do IIA Global, para demonstrar a tendência harmônica que tem sido estabelecida nos últimos anos também na esfera pública.

Dessa forma, a pesquisa cumpriu o seu objetivo e demonstrou com clareza que boa parte dos países filiados ao IIA estão em processo, já adotam ou adotam parcialmente as normas internacionais e, ainda, através da metodologia aplicada, a partir da edição da IN $\mathrm{n}^{\mathbf{0}}$ 3/2017-CGU, que o Brasil está adotando as normas internacionais de auditoria interna do IIA, como modo de alcançar legitimidade externa em razão dos pressupostos adotados mundialmente.

Por fim, recomenda-se outras pesquisas que proporcionem maiores esclarecimentos referentes às adoções de normas internacionais e as possíveis convergências realizadas. E os reflexos esperados após adoção destas normas.

\section{REFERÊNCIAS}

BRASIL. Constituição da República Federativa do Brasil, 1988. Disponível em:<http://www.planalto.gov.br/ccivil_03/constituicao/constituicaocompilado.htm>. Acesso em: 26 de jan. 2018.

Decreto $n^{0}$ 3.591, de 06 de janeiro de 2000. Dispõe sobre o sistema de controle interno do poder executivo federal e dá outras providências. Brasília, DF. Disponível em:< 
http:// http://www.planalto.gov.br/ccivil_03/decreto/d3591.htm>. Acesso em: 26 de jan. 2018.

CHRIST, Margaret H. ; MASLI, Adi ; SHARP, Nathan Y. ; WOOD, David A. Rotational internal audit programs and financial reporting quality: Do compensating controls help? Accounting, Organizations and Society, July 2015, Vol.44, pp.37-59

COSTA, A. J. B.; ALVES, A. A contribuição da auditoria interna para a governança: estudo de caso em uma organização social federal. Anais do XVI Congresso Internacional de Contabilidade e Auditoria (CICA), Aveiro, Portugal, 2017.

DIMAGGIO, P. J.; POWELL, W. W. A gaiola de ferro revisitada: isomorfismo institucional e racionalidade coletiva nos campos organizacionais. Revista de Administração de Empresas, 45(2), pp. 74-89, 2005. Disponível em: http://bibliotecadigital.fgv.br/ojs/index.php/rae/article/viewFile/37123/35894. Acesso em: 29 jan. 2018.

The iron cage revisited: institutional isomorphism and collective rationality in organizational fields. American Sociological Review, v. 48, p. 147-160, 1983.

HOQUE, Z. Methodological Issues in Accounting Research: Theories and Methods. London: Spiramus Press Ltd., 2010.

INSTITUTO DOS AUDITORES INTERNOS DO BRASIL. Disponível em: <http://www.iiabrasil.org.br/new/>. Acesso em: 25 jan. 2018.

MACHADO-DA-SILVA, C. L.; GONÇALVES, S. A. A Nota Técnica: A Teoria Institucional. In: Clegg, S. Handbook de Estudos Organizacionais: Modelos de Análise e Novas Questões em Estudos Organizacionais. (3. ed.) São Paulo: Atlas, 1999.

MARKS, N. Auditing governance processes: internal auditors should strongly consider a risk-based approach to audits of governance. Internal Auditor, Vol.69(1), p.39(4), 2012.

MEYER, J., SCOTT, W., DEAL, T. Institutional and technical sources of organisation structure: explaining the structure of educational organisation, in Meyer, J. W. and Scott, W. R. (Eds.), Organisational Environments, Russell Sage, New York, pp. 45-67, 1983.

MINISTÉRIO DA TRANSPARÊNCIA E CONTROLADORIA-GERAL DA UNIÃO. Manual de orientações técnicas da atividade de auditoria interna governamental do Poder Executivo Federal, 2017. Disponível em:

$<$ http://www.cgu.gov.br/Publicacoes/auditoria-e-fiscalizacao/arquivos/manual-deorientacoes-tecnicas-1.pdf $>$. Acesso em: 25 jan. 2018.

PIRES, Charline B. Critérios de Reconhecimento, Mensuração e Evidenciação de Heritage Assets: Um estudo comparativo em museus australianos, neozelandeses e ingleses utilizando os fundamentos da teoria institucional. Tese (Doutorado em Contabilidade) - Programa de Pós-Graduação em Ciências Contábeis, Universidade de Brasília, Brasília, 2018.

RUEF, M.; SCOTT, W. R. A multidimensional model of organizational legitimacy: hospital survival in changing institutional environments. Administrative Science Quarterly, v.43, p. 877-904, dez. 1998.

SCOTT, W. R. Introduction: Institutional theory and organizations. In: SCOTT, W. R., SOREN, C. The institutional construction of organizations: international and longitudinal studies. Thousand Oaks: Sage, 1995. 
SEEUWS, K. O Papel da Auditoria Interna no Setor Público. Anais do Seminário Internacional de Auditoria e Controle Interno - Brasília, DF, Brasil, 2014. Disponível em: <http://www.cgu.gov.br/Publicacoes/auditoria-e-fiscalizacao/arquivos/publicacao_seminariointernacional-de-auditoria-e-controle-interno.pdf >. Acesso em: 25 de jan. 2018

THE INSTITUTE OF INTERNAL AUDITORS. Normas Internacionais para a Prática Profissional de Auditoria Interna (Normas). Disponível em:

<https://global.theiia.org/Pages/globaliiaHome.aspx>. Acesso em: 26 de jan. 2018

VINTEN, Gerald. The future of UK internal audit education. Managerial Auditing Journal, Vol.19(5), pp.580-596, 2004.

\section{APÊNDICE}

\section{APÊNDICE A - Mensuração a aderência da IN no 3/2017-CGU às Normas internacionais de Auditoria do IIA}

\begin{tabular}{|c|c|c|c|c|c|c|}
\hline Categoria & Item & Normas & $\begin{array}{l}\text { Pontuação } \\
\text { Máxima }\end{array}$ & $\begin{array}{l}\text { "SIM"(1) } \\
\text { ou } \\
\text { NÃO(0)" }\end{array}$ & Pontuação & $\%$ \\
\hline \multirow{17}{*}{ 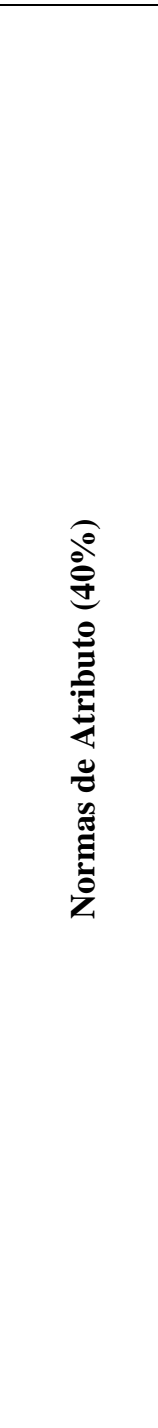 } & 1000 & $\begin{array}{l}\text { Propósito, Autoridade e } \\
\text { Responsabilidade }\end{array}$ & 100 & 1 & 100 & $1,54 \%$ \\
\hline & 1010 & $\begin{array}{l}\text { Reconhecimento das } \\
\text { Orientações Mandatórias } \\
\text { no Estatuto de Auditoria } \\
\text { Interna }\end{array}$ & 100 & 1 & 100 & $1,54 \%$ \\
\hline & 1100 & $\begin{array}{l}\text { Independência e } \\
\text { Objetividade }\end{array}$ & 100 & 1 & 100 & $1,54 \%$ \\
\hline & 1110 & $\begin{array}{l}\text { Independência } \\
\text { Organizacional }\end{array}$ & 100 & 1 & 100 & $1,54 \%$ \\
\hline & 1111 & $\begin{array}{l}\text { Interação Direta com o } \\
\text { Conselho }\end{array}$ & 100 & 1 & 100 & $1,54 \%$ \\
\hline & 1112 & $\begin{array}{l}\text { Papéis do Executivo } \\
\text { Chefe de Auditoria Além } \\
\text { da Auditoria Interna }\end{array}$ & 100 & 1 & 100 & $1,54 \%$ \\
\hline & 1120 & Objetividade Individual & 100 & 1 & 100 & $1,54 \%$ \\
\hline & 1130 & $\begin{array}{l}\text { Prejuízo à Independência } \\
\text { ou à Objetividade }\end{array}$ & 100 & 1 & 100 & $1,54 \%$ \\
\hline & 1200 & $\begin{array}{l}\text { Proficiência e Zelo } \\
\text { profissional Devido }\end{array}$ & 100 & 1 & 100 & $1,54 \%$ \\
\hline & 1210 & Proficiência & 100 & 1 & 100 & $1,54 \%$ \\
\hline & 1220 & Zelo Profissional Devido & 100 & 1 & 100 & $1,54 \%$ \\
\hline & 1230 & $\begin{array}{l}\text { Desenvolvimento } \\
\text { Profissional Contínuo }\end{array}$ & 100 & 1 & 100 & $1,54 \%$ \\
\hline & 1300 & $\begin{array}{l}\text { Programa de Garantia } \\
\text { de Qualidade e } \\
\text { Melhoria }\end{array}$ & 200 & 1 & 200 & $3,08 \%$ \\
\hline & 1310 & $\begin{array}{l}\text { Requerimentos do } \\
\text { Programa de Garantia de } \\
\text { Qualidade e Melhoria }\end{array}$ & 200 & 1 & 200 & $3,08 \%$ \\
\hline & 1311 & Avaliações Internas & 200 & 1 & 200 & $3,08 \%$ \\
\hline & 1311 & Avaliações Externas & 200 & 1 & 200 & $3,08 \%$ \\
\hline & 1320 & $\begin{array}{l}\text { Reporte do Programa de } \\
\text { Garantia de Qualidade e } \\
\text { Melhoria }\end{array}$ & 200 & 1 & 200 & $3,08 \%$ \\
\hline
\end{tabular}




\begin{tabular}{|c|c|c|c|c|c|c|}
\hline & 1321 & $\begin{array}{l}\text { Uso de "Em } \\
\text { conformidade com as } \\
\text { Normas Internacionais } \\
\text { para a Prática Profissional } \\
\text { de Auditoria Interna" }\end{array}$ & 200 & 0 & 0 & $3,08 \%$ \\
\hline & 1322 & $\begin{array}{l}\text { Divulgação de Não } \\
\text { Conformidade }\end{array}$ & 200 & 1 & 200 & $3,08 \%$ \\
\hline \multirow{27}{*}{ 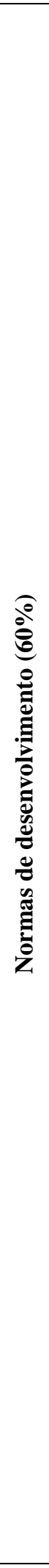 } & 2000 & $\begin{array}{l}\text { Gerenciamento da } \\
\text { Atividade de Auditoria } \\
\text { Interna }\end{array}$ & 100 & 1 & 100 & $1,54 \%$ \\
\hline & 2010 & Planejamento & 100 & 1 & 100 & $1,54 \%$ \\
\hline & 2020 & $\begin{array}{l}\text { Comunicação e } \\
\text { Aprovação }\end{array}$ & 100 & 1 & 100 & $1,54 \%$ \\
\hline & 2030 & $\begin{array}{l}\text { Gerenciamento de } \\
\text { Recursos }\end{array}$ & 100 & 1 & 100 & $1,54 \%$ \\
\hline & 2040 & Políticas e Procedimentos & 100 & 1 & 100 & $1,54 \%$ \\
\hline & 2050 & Coordenação e Confiança & 100 & 0 & $\mathbf{0}$ & $1,54 \%$ \\
\hline & 2060 & $\begin{array}{l}\text { Reporte para a Alta } \\
\text { Administração e o } \\
\text { Conselho }\end{array}$ & 100 & 1 & 100 & $1,54 \%$ \\
\hline & 2070 & $\begin{array}{l}\text { Prestadores de Serviço } \\
\text { Externo e a } \\
\text { Responsabilidade da } \\
\text { Organização sobre a } \\
\text { Auditoria Interna } \\
\end{array}$ & 100 & 0 & 0 & $1,54 \%$ \\
\hline & 2100 & Natureza do Trabalho & 100 & 1 & 100 & $1,54 \%$ \\
\hline & 2110 & Governança & 100 & 1 & 100 & $1,54 \%$ \\
\hline & 2120 & Gerenciamento de Riscos & 100 & 1 & 100 & $1,54 \%$ \\
\hline & 2130 & Controle & 100 & 1 & 100 & $1,54 \%$ \\
\hline & 2200 & $\begin{array}{l}\text { Planejamento do } \\
\text { Trabalho de Auditoria } \\
\text { Interna } \\
\end{array}$ & 200 & 1 & 200 & $3,08 \%$ \\
\hline & 2201 & $\begin{array}{l}\text { Considerações sobre o } \\
\text { Planejamento }\end{array}$ & 200 & 1 & 200 & $3,08 \%$ \\
\hline & 2210 & $\begin{array}{l}\text { Objetivos do Trabalho da } \\
\text { Auditoria }\end{array}$ & 200 & 1 & 200 & $3,08 \%$ \\
\hline & 2220 & $\begin{array}{l}\text { Escopo do Trabalho da } \\
\text { Auditoria }\end{array}$ & 200 & 1 & 200 & $3,08 \%$ \\
\hline & 2230 & $\begin{array}{l}\text { Alocação de Recursos } \\
\text { para o Trabalho da } \\
\text { Auditoria } \\
\end{array}$ & 200 & 1 & 200 & $3,08 \%$ \\
\hline & 2240 & $\begin{array}{l}\text { Programa de Trabalho da } \\
\text { Auditoria }\end{array}$ & 200 & 1 & 200 & $3,08 \%$ \\
\hline & 2300 & $\begin{array}{l}\text { Execução do Trabalho } \\
\text { da Auditoria }\end{array}$ & 100 & 1 & 100 & $1,54 \%$ \\
\hline & 2310 & $\begin{array}{l}\text { Identificação das } \\
\text { Informações }\end{array}$ & 100 & 1 & 100 & $1,54 \%$ \\
\hline & 2320 & Análise e Avaliação & 100 & 1 & 100 & $1,54 \%$ \\
\hline & 2330 & $\begin{array}{l}\text { Documentação das } \\
\text { Informações }\end{array}$ & 100 & 1 & 100 & $1,54 \%$ \\
\hline & 2340 & $\begin{array}{l}\text { Supervisão do Trabalho } \\
\text { da Auditoria }\end{array}$ & 100 & 1 & 100 & $1,54 \%$ \\
\hline & 2400 & $\begin{array}{l}\text { Comunicação dos } \\
\text { Resultados }\end{array}$ & 100 & 1 & 100 & $1,54 \%$ \\
\hline & 2410 & $\begin{array}{l}\text { Critérios para a } \\
\text { Comunicação }\end{array}$ & 100 & 1 & 100 & $1,54 \%$ \\
\hline & 2420 & $\begin{array}{l}\text { Qualidade das } \\
\text { Comunicações }\end{array}$ & 100 & 1 & 100 & $1,54 \%$ \\
\hline & 2421 & Erros e Omissões & 100 & 1 & 100 & $1,54 \%$ \\
\hline
\end{tabular}

GєCont, v.6, n. 1, Floriano-PI, Jan-Jun. 2019. 


\begin{tabular}{|c|c|c|c|c|c|}
\hline 2430 & $\begin{array}{l}\text { Uso de "Conduzido em } \\
\text { Conformidade com as } \\
\text { Normas Internacionais } \\
\text { para a Prática Profissional } \\
\text { de Auditoria Interna" }\end{array}$ & 100 & 0 & 0 & $1,54 \%$ \\
\hline 2431 & \begin{tabular}{|l|} 
Declaração de Não \\
Conformidade do \\
Trabalho da Auditoria \\
\end{tabular} & 100 & 1 & 100 & $1,54 \%$ \\
\hline 2440 & \begin{tabular}{|l|} 
Divulgação dos \\
Resultados \\
\end{tabular} & 100 & 1 & 100 & $1,54 \%$ \\
\hline 2450 & Opiniões Gerais & 100 & 1 & 100 & $1,54 \%$ \\
\hline 2500 & $\begin{array}{l}\text { Monitoramento do } \\
\text { Progresso }\end{array}$ & 100 & 1 & 100 & $1,54 \%$ \\
\hline 2600 & $\begin{array}{l}\text { Comunicação da } \\
\text { Aceitação de Riscos }\end{array}$ & 100 & 1 & 100 & $1,54 \%$ \\
\hline \multicolumn{2}{|r|}{ TOTAL } & 6500 & & 6.000 & $92,31 \%$ \\
\hline
\end{tabular}

